\title{
Our Human Population and the Planet
}

\author{
Milton H. Saier Jr.
}

Published online: 8 June 2007

(C) Springer Science + Business Media B.V. 2007

Projections released by the UN show the global human population is likely to rise by at least 2.5 billion to nearly 10 billion by 2050 . It is clear that the world needs to wake up to the devastating effect our species is having on the climate, our planetary ecosystems and human survival prospects.

Year after year, population figures are released that spell increasing crises for all of us. Yet they are met with a deafening silence. Everything we manage to achieve for the natural environment will be wiped out by the 70-80 million extra people each year who need space and resources to survive. Population is a sensitive issue, but it is time to stop worrying about causing offence or a possible backlash. We need to rein back human numbers, humanely and democratically, for the sake of the planet and all living organisms on it.

\footnotetext{
M. H. Saier Jr. $(\bowtie)$

Division of Biological Sciences (0116),

University of California, San Diego,

La Jolla, CA 92093-0116, USA

e-mail: msaier@ucsd.edu
}

Since our activities are the source of rising carbon dioxide emissions, each increment in the world's population makes it more difficult to tackle climate change. According to the Intergovernmental Panel on Climate Change, the annual average world per capita carbon emissions is 1.2 tons, or 4.4 tons of $\mathrm{CO}_{2}$. An extra 2.5 billion people would be expected to generate about 3 billion extra tons of volatile carbon. This is nearly twice the current emissions of the USA, which are roughly 1.6 billion tons of carbon per year, about one-third of the world's total.

All living organisms, including humans, are at risk from human population growth. The massive growth through the twentieth century has had more impact on biodiversity than any other single factor. The evidence is overwhelming: Environmental protection will be impossible to achieve with continued population growth in underdeveloped countries. Everyone must recognize the relationship between population and the environment and act accordingly. Appropriate action by developed countries including the USA involve funding birth control worldwide. This is estimated to cost about 40 billion dollars per year, a tiny fraction of the money the US taxpayer has been forced to pay for the devastating Iraq war. What a shame our dollars have not been spent to benefit humankind. 